\title{
IoT Enabled Process Innovation: Exploring Sensor-Based Digital Service Design Through an Information Requirements Framework
}

\author{
Niclas Carlén, August Forsman (D), Jesper Svensson ${ }^{(凹)}(\mathbb{D}$, \\ and Johan Sandberg $\mathbb{D}$ \\ Department of Informatics, Umeå University, 90187 Umeå, Sweden \\ \{niclas.carlen, august. forsman, jesper. svensson, \\ johan.sandberg\}@umu.se
}

\begin{abstract}
Through digitisation of physical artefacts and environments, the Internet of Things carries vast potential for process innovation. However, navigation of the quickly evolving technological landscape and identification of emerging opportunities for value creation remains challenging. To this end, we combine existing frameworks on information requirements, IT capability, and business value of IT. We evaluate the usability of these frameworks for IoT enabled innovation in our analysis of two sensor-based process innovation projects. We investigate the fit between process characteristics and technological functionality, and the implications of this alignment. Our analysis demonstrates that the framework provides a practically useful and theoretically coherent conceptual device for analyzing process characteristics and digital options to innovate processes. Furthermore, we find that IoT sensors are well suited to address connectivity and uncertainty requirements. However, in order to leverage them to address high equivocality requirements designers need deep contextual understanding to align IoT capability with information requirements.
\end{abstract}

Keywords: Process innovation $\cdot$ Internet of Things $\cdot$ Information requirements

\section{Introduction}

The ongoing pervasive digitisation of physical artefacts and environments, often collectively referred to as the Internet of Things (IoT), signifies a new paradigm in data processing and communication. It is not a new technology per se, Wortmann and Flüchter (2015) describes IoT as "a global infrastructure for the Information Society, enabling advanced services by interconnecting (physical and virtual) things based on, existing and evolving, interoperable information and communication technologies". IoT has evolved into an ecosystem of possible objects or things to connect to the internet where basically anything that has an on and off switch can be connected e.g. sensors. Combined with an expected battery life of several decades for many sensors allows for data collection around the clock. Sensors like this are making headway around the world with the emergence of smart cities, i.e. cities that are connected and efficient collecting data to manage its resources and serve its citizens in the best way 
possible (Sundmaeker et al. 2010). The global market for IoT is growing tremendously, resulting in significant market opportunities and an expected turnover at around 8.9 trillion dollars combined with an estimated 26-100 billion connected devices by the year 2020 (Statista 2017). Currently, there are significant uncertainties when companies engage in IoT; lack of standards, low understanding of technology and security issues are all sizeable problems hindering development (Forbes Insight 2017). Most companies feel uncertain which IoT-solution will collect the data they need, this results in a discrepancy in what companies need and what they get with regards to data and information (Forbes Insight 2017). In this paper, we argue that this uncertainty can be mitigated by synthesising two theoretical frameworks combining both analysis of information requirements and corresponding digital options with effects on processes by different IoT implementations.

We have been involved extensively in two IoT-projects and have seen issues regarding information requirements and process analysis arise throughout both. Both cases illustrate the need to understand the working environment and the technology at hand. While most studies thus far have focused either on the technical or business side of IoT (Forbes Insight 2017), we argue that there is a need to understand both aspects to generate successful outcomes. Since in most cases there is going to be humans interacting with the technology in their daily work life, we also argue that it is of great importance to understand the duality of technology and social activity. We have, therefore, focused on a micro-level perspective by investigating how IoT-systems affect work practices. This paper seeks to examine the effects of implementing sensor-based systems in organisations, i.e. how the implementation effects the process and value chain. This study will be limited to two separate case studies where sensor-based systems have been both designed and implemented in the organisations. Specifically, we explore the following research question:

How can IoT sensors be used for digital service design to innovate processes?

\section{Internet of Things in Business Processes}

With the emergence of ICT in the 20th century a lot of IT projects have had lacklustre results, one reason is the assumption that technological functionality solves organisational issues (Alter 2006). The argument against this is that an IT system should be viewed as a resource for the solution and not the solution itself (Alter 2006; Meyer et al. 2013). IoT is also argued to have a decentralising effect on the value chain in business as parts of it become connected. As the value chain becomes decentralised the decision-making rights are moved to the individual components in the chain, and the different parts become more independent, arguably creating a more efficient and streamlined process chain throughout (Haller et al. 2008). We would add to the current research by enacting these principles in real-world implementations. Doing so with the intention of showing real-world scenarios with the technology in place, we argue that the current body of research will benefit by the holistic perspective applied in this study. 


\subsection{A Framework for Analysing Process Effects with IoT and IoT Capability}

In this paper, we synthesise two different theoretical frameworks. The first is a framework developed to identify what digital options are available to organisations and what information requirements different processes have (Sandberg et al. 2014). The second framework is intended to measure the effects of the chosen solution on the process (Mooney 1995). By synthesising we refer to using the frameworks in tandem, iteratively, throughout the process analysis, implementation and evaluation of the systems. This in turn contributes to the body of research with a practical framework encompassing the entire process of implementing IoT in an organisation with intent to innovate business processes.

\section{Information Requirements}

Information requirements are used to identify what digital options there are for a specific business process. Digital options should here be understood as opportunities for leveraging IT in process innovation. The conceptualisation is grounded in earlier research, but Sandberg et al. (2014) further develop the concept of a specific tasks requirements about uncertainty and equivocality by adding connectivity to modernise the theory. We extend existing applications of the framework by using the information requirements in an IoT context. Establishing information requirements for each case is the first step of the innovative work process to map if and how IoT can support or transform a business process. This analysis, enables generation of the digital options available to organisations. To identify information requirements there are three aspects to consider and analyse: connectivity, uncertainty and equivocality.

Connectivity relates to the informational dependencies between processes and systems within an organisation, i.e. the need for information sharing across boundaries in an organisation (Malhotra et al. 2005). If the connectivity need is regarded as high, the focus for managers should be to counteract technical or social barriers by increasing information reach, characterised as "the number information sources that can be accessed during task execution" (Sandberg et al. 2014, p. 428). If information can be accessed across organisational and geographical boundaries, process information requirements have low connectivity requirements. When the connectivity need is low, it can be relevant to increase richness which refers to "the number of data points available regarding a given object during task execution" (Sandberg et al. 2014, p. 428).

Uncertainty refers to the availability and accuracy of information needed for actors to execute their task within an organisation. Uncertainty requirements can be addressed by continually balancing information production and information consumption (Ramaprasad and Rai 1996). Information production occurs when actors generate new information based on stimuli in the process and its environment. Information consumption turns the existing and available information into business process actions. If the information requirements are high in uncertainty, i.e. the current information is inaccurate, unreliable or insufficient, organisations should aim to increase production of information as they should not want to consume unreliable information. When uncertainty requirements are low, organisations can instead focus on consumption of 
information. If the information is reliable, available options for consumption emerge which can drive an organisation to make better data-driven decisions.

Equivocality refer to confusion and lack of mutual understanding when executing a task, or the level of complexity and ambiguity in the tasks information processing (Sandberg et al. 2014) (Mathiassen and Sørensen 2008). When a task is to be executed, there may be a need for mutual understanding between actors or processes, as they may have to rely on contextual knowledge. Conversely, there can be situations where actors or processes can rely on their codified knowledge and routines. If information requirements are high in equivocality, then the situation or task context is unknown for the involved parties. A relationship enables success in these situations; there needs to be a high level of understanding and trust within the system and in the systems supporting situational knowledge and contexts. If the requirements are low, however, then the characteristics are based on encounters where standardised protocols and workflows are utilised.

Table 1. Information requirements and digital options characteristic (Adapted from Sandberg et al. 2014)

\begin{tabular}{|c|c|c|c|}
\hline \multirow{3}{*}{$\begin{array}{l}\text { Information } \\
\text { requirement } \\
\text { Connectivity }\end{array}$} & \multicolumn{2}{|c|}{$\begin{array}{l}\text { Corresponding digital option } \\
\text { characteristic }\end{array}$} & \multirow{2}{*}{$\begin{array}{l}\text { Example of IoT capability } \\
\text { investment } \\
\text { Open data sharing of sensor } \\
\text { data between organisational } \\
\text { departments, generating easy } \\
\text { access to new information }\end{array}$} \\
\hline & High & $\begin{array}{l}\text { Reach: the number of } \\
\text { information sources that can be } \\
\text { accessed through IoT during } \\
\text { task execution }\end{array}$ & \\
\hline & Low & $\begin{array}{l}\text { Richness: the number of data } \\
\text { points available through IoT } \\
\text { about a given object during task } \\
\text { execution }\end{array}$ & $\begin{array}{l}\text { Flow sensors generating exact } \\
\text { measurements of waste flow in } \\
\text { a waste management facility }\end{array}$ \\
\hline \multirow[t]{2}{*}{ Uncertainty } & High & $\begin{array}{l}\text { Production: the extent to which } \\
\text { IoT supports the creation of } \\
\text { information from stimuli }\end{array}$ & $\begin{array}{l}\text { Multiple sensor measuring soil } \\
\text { and crop health in modern } \\
\text { agriculture }\end{array}$ \\
\hline & Low & $\begin{array}{l}\text { Consumption: the extent to } \\
\text { which IoT support translation of } \\
\text { information into action taken }\end{array}$ & $\begin{array}{l}\text { Heatmaps showing movement } \\
\text { patterns of visitors in a public } \\
\text { building }\end{array}$ \\
\hline \multirow[t]{2}{*}{ Equivocality } & High & $\begin{array}{l}\text { Relationship: extent to which } \\
\text { IoT supports contextual } \\
\text { consideration and development } \\
\text { of trust by adaptation and } \\
\text { sharing of information across } \\
\text { subsequent episodes }\end{array}$ & $\begin{array}{l}\text { Correct analysis of contextual } \\
\text { environment with the } \\
\text { implementation of sensors that } \\
\text { measure the exact values } \\
\text { needed for the task }\end{array}$ \\
\hline & Low & $\begin{array}{l}\text { Encounter: IoT based on a } \\
\text { standardised approach without } \\
\text { variation across customers; } \\
\text { limited regarding time and } \\
\text { flexibility but efficient due to } \\
\text { uniformity }\end{array}$ & $\begin{array}{l}\text { Photoelectric sensors measuring } \\
\text { visitors entering and leaving a } \\
\text { facility from a permanently } \\
\text { fixed position }\end{array}$ \\
\hline
\end{tabular}




\section{IoT Capabilities in Organisations}

Sandberg et al. (2014) refer to the organisation's IT capabilities as a firm's previous investments in IT resources, such as technology or IT competence. We use the concept and expand upon it to fit the field of IoT and thereby refer to them as IoT capabilities. Table 1 shows both information requirements, their corresponding digital options and examples of IoT capabilities that reflect the requirement characteristic.

\subsection{Measuring Effects of IoT on Processes}

We draw on Mooney's (1995) framework for assessing the business value of IT. Business performance is best measured from the performance of its processes (Ray et al. 2004; Mooney 1995). Sensors collect a limited range of data in an environment which in turn supports business processes. Therefore, we conclude that examining sensor implementation impact is most efficiently done in the context of the processes which they intend to support. In this study, we analyse the automational, transformational and informational effects of the IT-systems designed for each case, which are classifications derived from Mooney's process-oriented framework and have been used in similar studies (Stenmark and Jadaan 2010; Visich et al. 2009).

The automational dimension relates to how sensors data collection can substitute manual labour. Different kind of sensors can continuously collect data which are to support or initiate processes. Automational effects on business value are gained through aspects such as improved customer service, increased productivity and a more efficient labour distribution (Stenmark and Jadaan 2010; Visich et al. 2009).

Informational effects are those that are caused by IT-enabled collection, storage, processing and spread of information acquired from the sensors. Case studies of RFID implementations have shown that business value can arise from improved resource management and reduced manual labour (Stenmark and Jadaan 2010; Visich et al. 2009).

The transformational dimension affects and supports process innovation and transformation. Sensor data may support and improve existing processes but may also be utilised for business innovation. Data acquired to support a specific process chain can be used in combination with other aspects of the organisations' knowledge base to innovate the business (Stenmark and Jadaan 2010).

\section{Methodology}

For this paper we conducted a multiple case study consisting of two cases where sensor-based IoT-systems, through collection and visualisation of data, were designed and implemented to support different process chains. Case studies are a preferred strategy when research questions related to "how" and "why" are posed (Yin 2003), and multiple case-studies when the logic of the study is to "produce contrasting results but for predictable reasons" (Yin 2003, p. 47). We argue that this makes a case-study approach viable with regards to the framing and research question stated earlier. By evaluating this innovation process through multiple cases, we intend to generate general findings and propose practices which could be built upon in further research. 
We chose the cases based on an analysis of two different research sites. The classification for inclusion was that the case should present one or several concrete problems in a process chain where sensor-based technology could be a solution. These problems could either be a lack of ability in performing activities which could be enabled by the technology or addressing problems currently present in an organisation.

A process is "a structured, measured set of activities designed to produce a specified output for a particular customer or market" (Davenport 1993, p. 5) and can be classified into two different categories; operational processes and management processes (Mooney 1995). Operational processes are the set of activities an organisation performs to produce something that generates value and is referred to as an organisation's primary activities. Management processes are related to streamlining and improving the efficiency of an organisation's primary set of activities such as coordinating and handling different information. Process innovation in this context refers to the practice of analysing an organisation's processes and redesigning them using innovative technology to improve performance and support the processes (Davenport 1993). In this case, that innovative technology is LoRa-sensors, which enables remote monitoring and control of different aspects of a process, and the IT-artefacts of the software designed to visualise or manipulate the data generated by the sensors. Each case process chain was broken down into sub-processes depending on what type of activities and the complexity of the tasks performed. We then mounted sensors at each research site to collect data and designed IT-artefacts with the purpose of solving specific problems related to the sub-process. The effectiveness of these systems was analysed in the context of what type of value and effects the data generated when innovating operational and management processes.

\subsection{Research Sites and Sensor Technology}

The sensors used in the project are based on LoRa technology, and a specific type of gateway delivers connectivity to the sensors. Because of lacking infrastructure in the northern municipality, we were tasked to mount two base-stations; this implementation took place in September 2017. One of these base-stations was installed on the highest point in the town, which is a water tower, the other one on the roof of the local secondary school. We also installed a base-station in the city where the cleaning company project took place to further the existing coverage. The base-stations have guaranteed coverage of a $3 \mathrm{~km}$ radius, however, depending on disruption and quality of air it may be greater than that (LoRa-alliance 2015).

LoRa stands for Long Range and is the physical layer utilised to create long-range communication links. LoRa is based on chirp spread spectrum modulation, using its entire spectrum of bandwidth and is therefore very resistant to channel noise. LoRaWAN is based on Low Power, Wide-Area Networks i.e. LPWAN, and defines the communication protocol and system architecture for the network. LoRaWAN has a great influence on battery times for nodes, network capacity and security. LoRaWAN is explicitly designed for sensors and applications that need to send small amounts of data over long distances at different time intervals, making it ideal for IoT sensors applications. As IoT is still a new phenomenon and standards are currently lacking, other technologies are competing to become the business standard. In likeness with LoRa, 
several LPWAN networks are emerging as competitors; examples are Sigfox and Narrowband IoT that operate similarly (LoRa-alliance 2015).

In this study, we have used two different types of LoRa-sensors that measure different values while having some similar readings; temperature inside the casing, humidity at the sensor and battery-level (Table 2).

Table 2. LoRa Sensors utilised in projects with corresponding properties

\begin{tabular}{l|l}
\hline $\begin{array}{l}\text { Sensor } \\
\text { name }\end{array}$ & Properties \\
\hline ERS & Passive infrared (PIR) sensor registering movement in its field of view \\
\hline ELT-1 & $\begin{array}{l}\text { Analogue input sensor capable of coupling with external analogue } \\
\text { measurement tools, e.g. thermometer, voltmeter, ultrasonic level indicator }\end{array}$ \\
\hline
\end{tabular}

\subsection{Data Collection and Analysis}

The data collection process consisted of an analytical phase where we in conjunction with each organisation collected data regarding the problem background of their process chains. An implementation phase studying the physical environment of the research site, collected data relevant to the practical implementation of the system, and an evaluation phase where the data related to the results of the system was collected. All interviews conducted are semi-structured and were conducted throughout all three phases to capture viewpoints from the participants on both current problematic aspects, initial impressions of the implemented system, and impressions regarding its effects. Observations refer to activities where we have studied staff members performing the process chains, as well as documenting areas of interest. This was performed mainly during the analytical phase in order discover details relevant to mapping the process chains and capture insights possibly missed using the other methods. Workshops are meetings where we collected data related to our subsequent design choices and was mainly conducted in the analytical phase with participants in each innovation project. Informal encounters are the interactions with the organisation where we have performed different tasks or exchanged minor pieces of information related to the projects, a method which was applied throughout all three phases.

A total of 9 interviews, 11 observations, 7 workshops and 46 informal encounters were conducted, spanning all three cases in the study during a time frame spanning from 20th September 2017 to the 29th of Mars 2018 (Table 3).

Table 3. Data collection overview

\begin{tabular}{l|l|l|l|c}
\hline Case & Interviews & Observations & Workshops & Informal encounters \\
\hline Swimming pool & 4 & 5 & 2 & 7 \\
\hline Cleaning company & 5 & 6 & 5 & 39 \\
\hline
\end{tabular}


The data analysis was performed in iterations together with the organisation throughout the time-frame of the data collection, where the input in the analytical phase formed the basis for our description of the information requirements and IT-capabilities in each case. The results of the evaluation period (testing the systems in practice) formed the input for the process effects each system had on the corresponding process chain it supported.

\section{Results}

This section consists of the results of our research, each case will be presented with a description of the research site, problem background and information requirements of the process chains, with a subsequent description of practical implementation and effects from each case.

\subsection{Swimming Pool}

\section{Research Site}

The research site of the public swimming pool-case is in a municipality in the north of Sweden and is run by a small organisation of six people who maintain the pool, a gym and a gymnasium in the same building. The public pool is a facility open during weekdays and Saturdays on regular weeks.

\section{Process Chains and Problem Backgrounds}

The organisation lacks data on the number of visitors and which hours and days during the week generate most activity. The main areas of activity which the organisation found interesting were the entrance to estimate the overall number of customers, the cafeteria to investigate the air quality during peak hours, and the locker rooms to investigate differences in attendance between the genders. This data is interesting for the organisation when optimising staffing and air quality, and to create an overview of when and how much the facilities are used during the week. To achieve these informational effects, the sensor implementation sought to address the high uncertainty and low connectivity information requirements through continuous collection of visitor data. Further, the information regarding the number of visitors is non-equivocal as the collected data is readily interpreted in the context.

The second process chain in the case is optimising heating of the swimming pool. According to the person responsible for this routine, the pools are heated to $32{ }^{\circ} \mathrm{C}$ every week during Tuesday nights, and then the temperature falls successively to around $27{ }^{\circ} \mathrm{C}$ during the weekly cycle. This practice leads to uncertainty amongst the customers on the current temperature and generates phone calls to the organisation increasing the workload. Further, the facilities have shown signs of increased wear in forms of mould and moisture damage due to the increased evaporation generated by higher temperatures. The organisation seeks informational effects on the managerial level through an increased amount of temperature data points and implementing sensors to address the connectivity and uncertainty requirements. The equivocal requirements were low as temperature data is readily understood in the context. 
The third process chosen for this case is the documentation of pool water quality, which is a process chain performed by the staff daily to discover anomalies and potential health risks related to the pool water. Water samples are collected, analysed and documented as the first task of every day: water temperature, $\mathrm{pH}$-value and chlorine-levels. To collect this data, the staff places a thermometer in the pool water where it is submerged for 15 min. During this time, they gather two water samples which are analysed using a pool water quality kit establishing its $\mathrm{pH}$-value and amount of chlorine. This data is then documented manually in a binder and stored in the staff office of the facilities. Due to the repetitive manner of the data collection and documentation, the organisation seeks to explore to what extent it could be automated using IoT sensors. To achieve these effects, automatic production of information regarding temperature, $\mathrm{pH}$-value and chlorine levels is required, which characterises an information requirement high in uncertainty. We found the connectivity and equivocality requirements to be low as the information is to be utilised within task entity boundaries and well understood in the context.

\section{Implementation}

To support the first process chain, we mounted four sensors at areas for which the organisation had expressed interest. The main units of observation these sensors were to measure were motion activity and temperature in each respective area. The sensors were placed at the entrance of each respective area at the height of around $150 \mathrm{~cm}$ 's ensuring measurements of every individual passing.

This motion activity and temperature-data is uploaded every $30 \mathrm{~min}$ to a database, imported into tables and transformed into graphs, both real-time and historical. The information was made accessible to the organisation through a web application where it could be studied and form part of the basis for process innovation. The implemented system has the characteristics referring to the production of information to address uncertainty requirements. As this process aims to collect information about motion and temperature in the facility we argued that the four sensors would address the uncertainty requirements.

To support the second chain, we mounted one temperature sensor in the bottom of the swimming pool, hidden behind a ladder. This sensor uploaded water temperature every $30 \mathrm{~min}$ to a database and was imported into tables and graphs made available to the organisation. The historical data generated by the sensor can be utilised to measure how much time it takes to heat the pool to the preferred temperature and get a more detailed overview of its heating cycle. This data could serve as a basis for innovating the heating process chain and minimise the problems of their current practices. The third process chain utilised the same temperature sensor as the second as the only relevant unit in the process chain collected and documented is the temperature data. This data was then uploaded every $30 \mathrm{~min}$ and presented in the form of tables and graphs. For this process, we addressed the information requirements with the intent to increase richness by collecting data with the sensor as well as produce more information to lower uncertainty.

\section{Effects}

The first process chain showed primarily informational effects. The data collected from the motion sensors generated an estimate of which areas has the most activity, and 
during which hours can be established by studying the graphs in the web application. The organisation had ideas of using the data to optimise the air conditioning. However, the functional capabilities of adjusting the air conditioner cycles to reflect usage or be automated by the data seemed to be limited which was uncovered later in the project when this issue was discussed with a janitor responsible for the air conditioning. A side-effect of studying the comprehensive dataset was the discovery that the temperature in the cafeteria rises around $2-3{ }^{\circ} \mathrm{C}$ during the nights when the facility is closed. This occurrence was unknown to the organisation when they were informed of it, and according to one of the staff members, may be related to the underfloor heating being active during the night time when the ventilation is inactive.

The effects on the second process chain had informational effects. The historical data generates a clear and consistent timeframe over how long it takes for the swimming pool to reach its intended temperature and shows some anomalies. An example is the re-warming of the pool, which usually happens around $4 \mathrm{~h}$ after it has reached its maximum temperature. Why this happens is unknown to us right now but will be of interest in further evaluation of the system. The third process chain has potential to be completely automated, generating both automational and transformational effects, but since the sensors automate only $1 / 3$ of the data collection, the staff must still perform a majority of the process chain in the same manner as before. A future update of the system will be to implement sensors collecting data of the chlorine level and $\mathrm{pH}$-value. With a complete system in place, the whole process will be performed continuously and automatically document the data in the same way as current practice. The permanent character enables transformational possibilities in the sense that with a system documenting the water quality continuously, anomalies in the water can be discovered faster.

\subsection{Cleaning Company}

\section{Research Site}

The research site for the case of the cleaning company is located in a university building. The organisation is responsible for cleaning all facilities and have a staff of six managing and executing this task at the research site.

\section{Process Chains and Problem Backgrounds}

The staff have expressed a problem of prioritising which order that classrooms are cleaned after the weekend in an effort to work more condition-based. The current situation is such that the activity in the classrooms during the weekends is unknown to the staff when they begin cleaning on Mondays, and they clean each room in a set routine. The consequence of cleaning in a routine-based manner could result in rooms with less cleaning needs getting cleaned, and rooms with higher cleaning need left unattended. The cleaning process of each room constitutes four sub-processes: cleaning the floor, cleaning the tables, wiping the whiteboard and emptying the waste bin, and the cleaning need of each sub-process in combination is what constitute the cleaning need of the classroom. The organisation seeks informational effects through collection of information regarding classroom cleaning need. This information requirement has the characteristics of high equivocality, as assessing cleaning need is non-algorithmic 
and is based on situated knowledge about the specific context. The process chain has high connectivity and both high and low uncertainty requirements as cleaning need information must be collected and accessed remotely. Since the organisation currently lacks data on the activity in the classrooms during the weekends, it cannot innovate its processes in such a way that it aligns with the ambition of working more conditionbased.

The second process chain presented as problematic by the organisation is assessing if a room is vacant. In the current situation, the staff do not clean rooms which are occupied and wait until the rooms are vacant to clean them. This problem means in practice that they sometimes spend time visiting rooms only to discover that they cannot be cleaned, and delay that process until later, having wasted time moving to the classroom. The organisation seeks informational effects on the operational level through remote access to information with regards to classroom vacancy. To achieve these effects, vacancy information need to be produced and remotely accessible to cleaning staff, which characterises the information requirements as high in connectivity and uncertainty. Lastly, information regarding classroom vacancy is non-equivocal as the room is either vacant or not.

The third process chain is the comparison between the presumed usage based on the booking schedule and actual usage of the specific classrooms. According to the organisation, it is not uncommon for a room to be booked during the week, but its actual usage is unclear. The staff can plan the cleaning of classrooms only to discover that they have not been used and, therefore, not in need of cleaning. This could also be used as a basis when negotiating terms with its currently largest customer which is the university itself. Part of how many hours the company can bill the university is based on the number of hours booked in the electronic booking schedule. The organisation seeks informational effects on the managerial level through remote information collection of classroom usage. High connectivity, high uncertainty, and low equivocality characterises its information requirement. The multiple data collection points increase reach and production of this non-equivocal information.

\section{Implementation}

To support the process chains described in the case we mounted sensors in classrooms collecting motion data. The sensors were placed at the entrance around $170 \mathrm{cms}$ from the floor, registering every motion near the entrance door. This data was uploaded every $10 \mathrm{~min}$ to a database. We then designed a web-application containing various artefacts which utilise this data to address the information requirements in the process chain. Due to the high connectivity requirements the purpose was to increase reach through multiple data collection points. For the uncertainty requirements, there was a need for both production and consumption to address the requirements relating to uncertainty. The sensors installed addressed the information production aspect, and the web application was developed to increase consumption of information. As the equivocality requirements were high, the need for a relationship characteristic was of high priority. Due to the organisation wanting to measure cleaning need in the rooms, which is a highly equivocal measurement, the sensors and web application needed to be utilised in conjunction with the cleaning staffs' knowledge and routines. 
The artefacts contained in the application display three sets of data; accumulated motion in each room, a two colour-button signalling if motion has been detected the last $10 \mathrm{~min}$ and historical data available for export in the form of graphs. The application was made accessible for the cleaning staff in their day-to-day work by a tablet placed on their cleaning cart.

The system was tested for three weeks, during which the staff had access and utilised it when performing their tasks. Furthermore, they graded the experienced cleaning need which was defined on a three-grade scale where one was clean, two was normal and three related to a high cleaning need. Interviews with the staff were conducted before, during and after the test period. During this period, we also tested the hypothesis that an increased motion value from a classroom during the weekend represents a higher cleaning need. This hypothesis was tested by photographing every aspect related to the sub-processes of the cleaning process chain after the weekends, comparing the empirical findings with motion data captured by the sensors.

\section{Effects}

The implemented system had various effects on the organisation depending on which process chain it supported, but how well it improves the general organisational performance remains inconclusive and needs to be evaluated further. Although the system generated the motion data we presumed when designing and implementing the system, the usability of this data in the context of the first process chain, determining the cleaning need of a specific classroom, is still unclear. The system was designed to have mainly informational effects on the first process chain, by presenting information to the staff which could be used to determine which classrooms that had a more significant cleaning need. The empirical findings, however, related to the hypothesis that higher motion value represents a higher cleaning need are vague. We believe that further evaluation of the system is necessary to establish its effects.

The effects on the second process chain, which was to inform the staff if a classroom is vacant and possible to clean, has mainly been of informational and automational character, with the intended ability successfully generated. According to the staff, the system correctly identifies if a classroom is vacant or if there are students present, which informs them in a way that improves their performance. Since they do not have to spend time collecting this information manually, it has automated the process chain. The long-term effects of having this ability, its possible flaws (no motion input if students are very still) and how great of a value it brings to the organisation, due to it solving a relatively minor problem, will have to be further evaluated.

The system has generated the desired ability to analyse and compare between the booked hours in the electronic booking schedule and the actual amount of activity in the classrooms, which would classify it as having a transformational effect on the organisation's ability to innovate. This ability may contribute to having informational effects which improve performance, depending on how generated data is utilised. The organisation has expressed an ambition to integrate the graphs, and sensor data with the current electronic booking schedule to easier compare the data, but this feature has yet to be implemented. 


\section{Discussion}

To provide actionable guidance for the use of IoT sensors to innovate processes through digital service design, we have illustrated the applicability of a synthesised framework facilitating opportunity recognition, design and analysis of effects. The analysis provides insight both to the general applicability of the framework across the innovation process, and the bearing of specific components of the framework for IoT sensors.

Although developed for different tasks, our application of the framework suggests that it is beneficial to apply the whole chain of analysis in the different subparts of the innovation process. While the business value of IT provides support for retrospective analysis of effects (Stenmark and Jadaan 2010; Visich et al. 2009), the desired outcomes in terms of informational, automational and transformational effects should guide the design of the digital service system. Thus, in accordance with Alters (2006) arguments regarding a holistic view in systems design, such ambitions need to be considered in the initial analysis phase. By establishing information requirements for a process chain or specific sub-processes during this phase, potential complexities related to generating the desired effects can be discovered, e.g. processes with a high level of equivocality. With a desirable effect-outcome and the information requirements necessary for generating this outcome established, we argue that this provides a more wellgrounded basis for process innovation with sensors.

For sensor-based process innovation, the process information requirements in part determine the degree of automational effect that can be achieved. A process with the purpose of simply collecting or communicating one type of data may be automated in its entirety through implementing a sensor-based system. Automational effects of this kind are shown in the swimming pool case where the process chain of documenting pool water quality has the potential of being automated completely by the utilisation of sensor-based systems. This high degree of automational effects arises from alignment between information needed to complete the task and sensor capacity to produce data output. This outcome differs from a process with high equivocal information requirements, such as the process of evaluating the cleaning need where there are four sub-processes to complete the process chain. Each sub-process requires information with regards to its specific cleaning need, and the sum of the informational output from these sub-processes are then what constitutes the cleaning need of the classroom. The sensor used to support this process chain provides information of movement around the entrance to the classroom. This information of movement does not map precisely to any of the sub-process outputs of assessing a cleaning need. For example, to assess if a whiteboard needs cleaning there is a requirement of visual examination of the whiteboard and from this draw a conclusion regarding its need for cleaning. Information of movement is only a proxy variable that does not directly respond to use of the whiteboard. Similarly, to assess if the floor needs mopping, information is required on the amount of dust and dirt that is currently present on its surface. Again, the type of information provided by the sensor used does not immediately support an assessment of mopping need.

The sensor-produced data may be used to make assumptions of cleaning need based on the information of activity around the sensor, without showing a one to one relationship between the amount of movement and the equivocal cleaning need. For 
instance, while movement information does not show how dusty or dirty the floor is, it shows the cause of this effect: people have walked on the floor. Any value of activity data means that the floor has been walked upon. If the floor has been walked upon, it is reasonable to assume that some amount of dirt and dust have been transferred from the shoes to the surface of the floor. Thus, a value of activity data increases the need of mopping the floor.

This reasoning may be used on the other sub-processes of the cleaning case as well, though with a weaker conclusion. We have argued that movement information show a relationship with the degree of dirt on the floors. However, movement information is not directly correlated with the use of whiteboards. Recorded activity data means that there has been a person around the entrance of the classroom. It does, however, not capture the type of activity the person has engaged in, e.g. if they used the whiteboards. Similarly, the data does not show if the person(s) moving close to the classroom entrance also throw waste into the waste bin. The IoT sensor capabilities do not address these equivocal information requirements directly. Thus, conclusions regarding the cleaning need of these processes cannot be drawn solely from the information provided by the sensor. Movement information may, however, be used in conjunction with visual evaluation of the state of classrooms over time to show statistical probabilities of whiteboard cleaning need, waste bin level and table dirt. Cleaning staff collected this data during the testing phase of the cleaning case by grading the classrooms total cleaning need in conjunction with them cleaning it. This method of evaluation could be improved by splitting it into an evaluation of each sub-process, thus increasing its accuracy. There are degrees to this relationship between process information requirements and sensor data output. This relationship spans from misaligned, exemplified by assessing cleaning need of whiteboards with movement sensors, to aligned, as shown by addressing temperature requirements with a temperature sensor. Thus, we argue that IoT sensors could be implemented to processes with various degrees of success depending on the process equivocality information requirements (Table 4).

Table 4. General descriptions of IoT capabilities addressing information requirements.

\begin{tabular}{l|l}
$\begin{array}{l}\text { High connectivity } \\
\text { Reach }\end{array}$ & $\begin{array}{l}\text { IoT-sensors by nature increases reach due to many individual data } \\
\text { collection points that are accessible over organisational borders }\end{array}$ \\
\hline $\begin{array}{l}\text { High uncertainty } \\
\text { Production }\end{array}$ & $\begin{array}{l}\text { IoT-sensors can continuously produce data outside human intervention, } \\
\text { day as night }\end{array}$ \\
\hline $\begin{array}{l}\text { High equivocality } \\
\text { Relation }\end{array}$ & $\begin{array}{l}\text { IoT-sensors can supply relations, however, important to match sensor } \\
\text { capabilities with the process information requirements }\end{array}$ \\
\hline $\begin{array}{l}\text { Low connectivity } \\
\text { Richness }\end{array}$ & $\begin{array}{l}\text { IoT-sensors add richness and granularity due to continuous, focused data } \\
\text { collection }\end{array}$ \\
\hline $\begin{array}{l}\text { Low uncertainty } \\
\text { Consumption }\end{array}$ & $\begin{array}{l}\text { IoT-sensors do not directly address consumption, but through data- } \\
\text { analysis and visualisation of sensor-data consumption can be addressed }\end{array}$ \\
\hline $\begin{array}{l}\text { Low equivocality } \\
\text { Encounter }\end{array}$ & $\begin{array}{l}\text { IoT-sensors can fortify encounters through stabile data collection that } \\
\text { supports codified knowledge and routine-based tasks }\end{array}$ \\
\hline
\end{tabular}




\section{Conclusion}

In this paper, we provide a synthesised framework for IoT sensor-based process innovation. The framework draws on extant theory on (1) the role of information requirements analysis in identification of IT-based process innovation opportunities and (2) effects on business value. The synthetisation of these theoretical devices enables a holistic analysis, from opportunity recognition to evaluation of achieved effects. We have explored the practical usability of the framework through an analysis of two different implementations of IoT systems and associated organisational effects. We found areas where the sensors have shown potential for process innovation and demonstrated the applicability of an information requirements perspective in an IoT context. Through this we have been able to identify areas where complexity becomes an issue for implementation of IoT systems. In particular, the results point to IoT sensors general capacity for responding to high connectivity and uncertainty requirements, and the need for aligning functionality with organisational needs to respond to high equivocality requirements. Thus, the functionality provided by IoT sensors does not reduce the importance of organisational ability for process analysis and identification of values to measure. We also identify the effects and relate them to levels of alignment between information requirements in the process and sensor capacity. Lastly, we have argued for a need to understand IoT through a micro-level perspective in organisational processes and proposed a set of practices for overcoming challenges encountered in the cases. As the field continues to grow we believe it is essential for organisations to further understand how to utilise IoT-technology when innovating their work processes.

\section{References}

Alter, S.: The Work System Method, 1st edn. Work System Press, Larkspur (2006)

Davenport, T.H.: Process Innovation - Reengineering Work Through Information Technology, 1st edn. Harvard Business School Press, Boston (1993)

Insight, F.: Internet of Things - From Theory to Reality. Forbes Insight, Jersey City (2017)

Haller, S., Karnouskos, S., Schroth, C.: The Internet of Things in an Enterprise Context. Springer, Vienna (2008). https://doi.org/10.1007/978-3-642-00985-3_2

LoRa-alliance: LoRaWAN - What is it? A technical overview of LoRa and LoRaWAN, San Ramon, CA: LoRa ${ }^{\circledR}$ Alliance Technical Marketing Workgroup (2015)

Malhotra, A., Gosain, S., Sawy, O.: Absorptive capacity configurations in supply chains: gearing for partner-enabled market knowledge creation. MIS Q. 29, 145-187 (2005). https://doi.org/ $10.2307 / 25148671$

Mathiassen, L., Sørensen, C.: Towards a theory of organizational information services. J. Inf. Technol. 23, 313-329 (2008). https://doi.org/10.1057/jit.2008.10

Meyer, S., Ruppen, A., Magerkurth, C.: Internet of Things-Aware Process Modeling: Integrating IoT Devices as Business Process Resources. Springer, Valencia (2013). https://doi.org/10. 1007/978-3-642-38709-8_6

Mooney, J.G.: A Process Oriented Framework for Assessing the Business Value of Information Technology. Center for Research in Information Technology and Organizations, University of California, Irvine (1995) 
Ramaprasad, A., Rai, A.: Envisioning management of information. Omega. 24, 179-193 (1996). https://doi.org/10.1016/0305-0483(95)00061-5

Ray, G., Barney, J., Muhanna, W.: Capabilities, business processes, and competitive advantage: choosing the dependent variable in empirical tests of the resource-based view. Strateg. Manag. J. 25, 23-37 (2004). https://doi.org/10.1002/smj.366

Sandberg, J., Mathiassen, L., Napier, N.: Digital options theory for IT capability investement. J. Assoc. Inf. Syst. 15(7), 422-453 (2014)

Statista: Statista - The statistics portal (2017) https://www.statista.com/statistics/512673/ worldwide-internet-of-things-market/. Använd 13 March 2018

Stenmark, D., Jadaan, T.: Enabling process innovation through sensor technology: a multiple case study of RFID deployment. In: ECIS 2010 Proceedings, Gothenburg (2010)

Sundmaeker, H., Guillemin, P., Friess, P., Woellflé, S.: Vision and Challenges for Realising the Internet of Things. Publications Office of the European Union, Luxemburg (2010)

Visich, J.K., Li, S., Khumawala, B.M., Reyes, P.M.: Empirical evidence of RFID impacts on supply chain performance. Int. J. Oper. Prod. Manag. 29(12), 1290-1315 (2009)

Wortmann, F., Flüchter, K.: Internet of things - technology and value added. Bus. Inf. Syst. Eng. 57(3), 221-224 (2015)

Yin, R.: Case Study Research, 3rd edn. SAGE Publications, Thousand Oaks (2003)

Open Access This chapter is licensed under the terms of the Creative Commons Attribution 4.0 International License (http://creativecommons.org/licenses/by/4.0/), which permits use, sharing, adaptation, distribution and reproduction in any medium or format, as long as you give appropriate credit to the original author(s) and the source, provide a link to the Creative Commons license and indicate if changes were made.

The images or other third party material in this chapter are included in the chapter's Creative Commons license, unless indicated otherwise in a credit line to the material. If material is not included in the chapter's Creative Commons license and your intended use is not permitted by statutory regulation or exceeds the permitted use, you will need to obtain permission directly from the copyright holder.

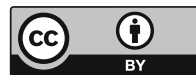

